\title{
The immune response to resistive breathing
}

\author{
T. Vassilakopoulos, C. Roussos, S. Zakynthinos
}

The immune response to resistive breathing. T. Vassilakopoulos, C. Roussos, S. Zakynthinos. (C) ERS Journals Ltd 2004.

ABSTRACT: Resistive breathing is an "immune challenge" for the body, initiating an inflammatory response consisting of an elevation of plasma cytokines, and the recruitment and activation of lymphocyte subpopulations. These cytokines do not originate from monocytes, but are, instead, produced within the diaphragm, secondary to the increased muscle activation.

Oxidative stress is a major stimulus for the cytokine induction, secondary to resistive breathing. The production of cytokines within the diaphragm may be mediating the diaphragm muscle fibre injury that occurs with strenuous contractions, or contributing towards the expected repair process. These cytokines may also compromise diaphragmatic contractility or contribute towards the development of muscle cachexia. They may also have systemic effects, mobilising glucose from the liver and free fatty acid from the adipose tissue to the strenuously working respiratory muscles. At the same time, they stimulate the hypothalamic-pituitary-adrenal axis, leading to production of adrenocorticotropin and $\beta$-endorphins.

The adrenocorticotropin response may represent an attempt of the organism to reduce the injury occurring in the respiratory muscles via the production of glucocorticoids and the induction of the acute phase-response proteins. The $\beta$-endorphin response would decrease the activation of the respiratory muscles and change the pattern of breathing, which becomes more rapid and shallow, possibly in an attempt to reduce and/or prevent further injury to the respiratory muscles.

Eur Respir J 2004; 24: 1033-1043. Dept of Critical Care and Pulmonary Services,
University of Athens Medical School, Evangelismos Hospital, Athens, Greece.

Correspondence: T. Vassilakopoulos

Critical Care Dept

Evangelismos Hospital

45-47 Ipsilandou Str

GR-10675 Athens

Greece

Fax: 3017216503

E-mail: tvassil@med.uoa.gr

Keywords: Control of breathing

exercise immunology

interleukin-6

oxidants/antioxidants

respiratory immunology

respiratory muscle

Received: June 82004

Accepted after revision: August 172004
Resistive breathing is encountered in many disease states, such as asthma and chronic obstructive pulmonary disease (COPD). Asthma and COPD are associated with significant airway inflammation, with elaboration of various cytokines within the airways. When strenuous enough, inspiratory resistive breathing produces diaphragmatic fatigue [1] and diaphragmatic structural injury [2, 3]. In this report, the current authors review recent evidence that resistive breathing per se is an "immune challenge" initiating an inflammatory response in the body. Potential implications that this immune response might have for respiratory failure are also discussed.

\section{The immune response to inspiratory resistive breathing}

Strenuous whole-body physical exercise, in the form of long-distance running, treadmill and cycle ergometry, has been shown to increase the level of circulating cytokines. Thus, increased plasma levels of tumour necrosis factor (TNF)- $\alpha$, interleukin (IL)-1 $\beta$, IL-1 receptor antagonist, TNF receptors, IL-10, IL-8, and macrophage inflammatory protein-1 are found after strenuous exercise [4].

Inspiratory resistive breathing represents a form of "exercise" for the respiratory muscles. Accordingly, when healthy normal volunteers were subjected to resistive breathing $(45 \mathrm{~min}$ at $75 \%$ of their maximum inspiratory pressure through alinear inspiratory resistance with unloaded expiration), the plasma levels of IL- $1 \beta$ and IL- 6 and TNF- $\alpha$ were significantly elevated (figs 1 and 2) [5, 6].

Not only were plasma cytokines elevated, but preliminary data suggest that specific lymphocyte subpopulations were also recruited and activated. Accordingly, flow cytometric analysis of blood derived from these subjects, with incubation of lymphocytes with monoclonal antibodies against cell surface antigens characterising their subpopulation and activation state, showed that the immunofluorescence of positive cells for CD3-/CD16/56+, CD3/CD8 and CD8/ CD45RA was increased after the resistive breathing session, which means that strenuous resistive breathing increases the percentage of $\mathrm{T}$-cytotoxic lymphocytes, $\mathrm{T}$-cytotoxic naïve lymphocytes and natural killer cells [7].

Thus, strenuous resistive breathing induces an immune response consisting of the elevation of plasma cytokines, and the recruitment and activation of lymphocyte subpopulations.

\section{The origin of resistive breathing-induced plasma cytokines}

The source of the resistive breathing-induced cytokines was not known. Blood monocytes are a major, though not an exclusive, source of immuno-inflammatory mediators [8]. When activated by various stimuli, they release a cascade of cytokines, including TNF- $\alpha$, IL-1 $\beta$ and IL-6 [8]. Thus, it was hypothesised that activated blood monocytes are a likely source of cytokine production during strenuous resistive breathing, given that intense exercise induces (apart from cytokines) endotoxaemia [9], and leukocyte mobilisation and activation [10]. Six healthy subjects performed resistive breathing sessions at $75 \%$ of maximum inspiratory pressure. Monocytes were isolated from blood, and were made permeable (with saponin treatment) and incubated with fluorescent 

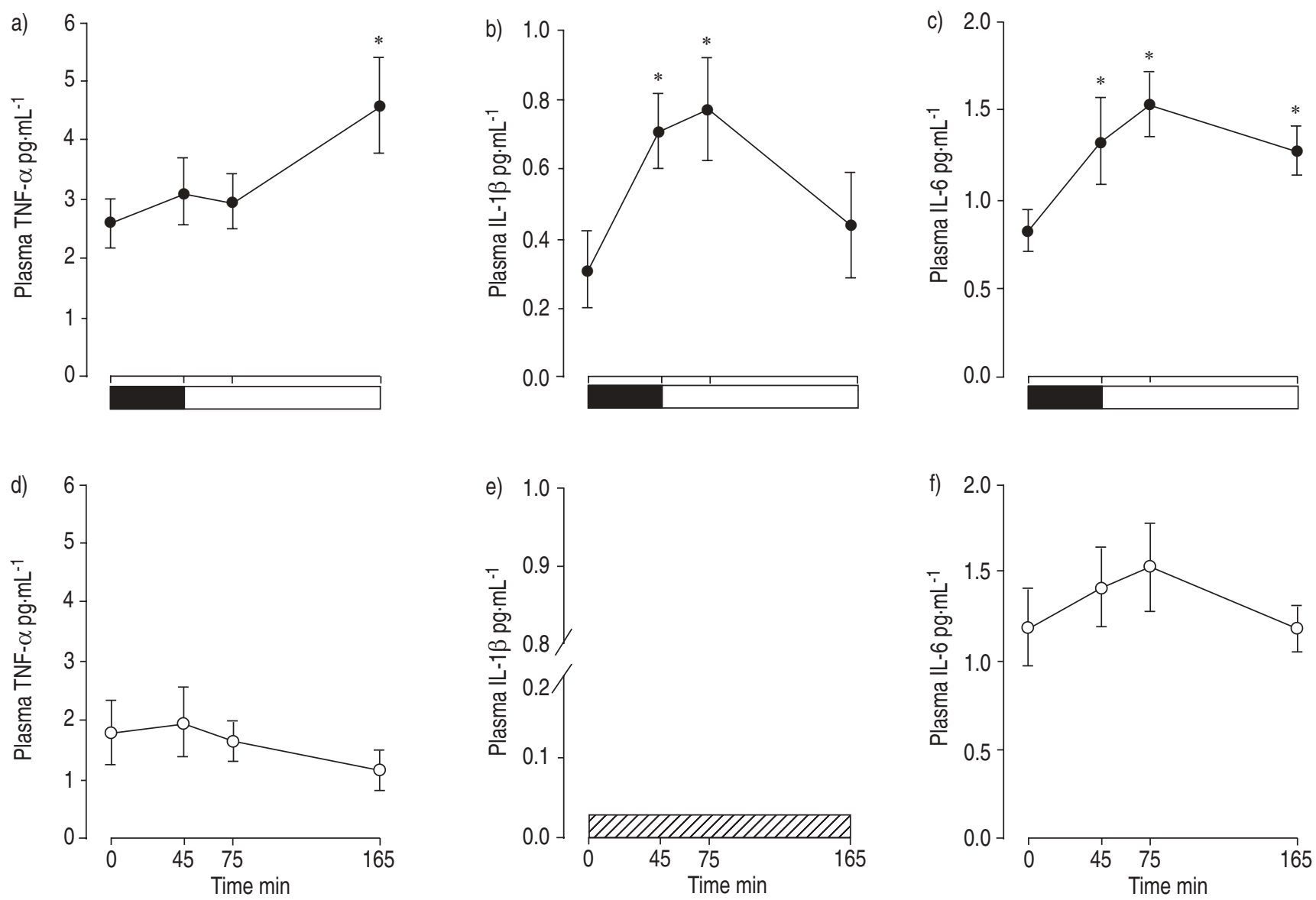

Fig. 1. - The plasma cytokine response to resistive breathing before $(\bullet ; a, b$ and $c)$ and after $(\bigcirc$; d, e and f) antioxidants. The mean plasma tumour necrosis factor (TNF)- $\alpha$ (a and d), interleukin (IL)-1 $\beta$ (b and e), and IL-6 concentrations (c and f) before the resistive breathing session ( $0 \mathrm{~min}$ ), at the end of resistive breathing ( $\mathbf{\square}$ : load; $45 \mathrm{~min}$ ), and 30 and $120 \mathrm{~min}$ after the end of resistive breathing ( $\square$ : recovery; i.e. $75 \mathrm{~min}$ and 165 min after the beginning of the resistive breathing session) were recorded. The plasma IL-1 $\beta$ was below detection limit after antioxidant supplementation ( $\mathbb{Z} ; \mathrm{e})$. *: $\mathrm{p}<0.05$ compared with baseline values $(0 \mathrm{~min})$. Modified from [6] with permission.

monoclonal antibodies against TNF- $\alpha$, IL-1 $\beta$ and IL-6 [6]. Intracellular flow cytometric detection of cytokines was used, which allows for the sensitive determination of cytokine production by specific cell types, since it measures the amount of protein arrested at the Golgi complex of a specific cell population at a specific time point [11]. Neither the percentage, nor the absolute number of cytokine-positive monocytes increased in response to resistive breathing [6]. The mean fluorescence intensity, a rough estimate of the amount of cytokine production by cytokine-positive cells [11], was also not altered by resistive breathing. Furthermore, no correlation was found between the level of cytokine expression in monocytes and the plasma level of cytokines. Thus, although a role for monocytes in the baseline plasma level of cytokines cannot be excluded, monocytes do not contribute to the resistive breathing-induced plasma cytokine elevation.

Studies using various techniques have established that skeletal muscles exhibit a low level of constitutive expression of various cytokines, such as TNF- $\alpha$ [12], IL-1 $\beta$ [13], and IL-6 [14]. Since strenuous muscular contractions increase IL-6 production within skeletal muscles [14], it was hypothesised that cytokines are induced in the diaphragm in response to acute resistive loading [15]. Anaesthetised, tracheostomised, spontaneously breathing adult Sprague-Dawely rats were subjected for 1,3 or $6 \mathrm{~h}$ to inspiratory resistive loading, corresponding to $45-50 \%$ of the maximum inspiratory pressure. Rats that were subjected to the same procedures and allowed to breathe spontaneously for equal time periods with no load served as controls. The diaphragm and the gastrocnemius muscles were excised at the end of the loading period, and mRNA expression of 11 cytokines and two housekeeping genes (L32, glyceraldehyde-3-phosphate dehydrogenase) was analysed in these muscles using a multi-probe ribonuclease protection assay system (RiboQuant; Pharmingen, San Diego, CA, USA). IL-6, and to a lesser extent IL-1 $\beta$, TNF- $\alpha$, IL-4, IL-10 and interferon (IFN)- $\gamma$, were significantly increased in a time-dependent manner in the diaphragm of animals subjected to inspiratory resistive loading. No changes in cytokine expression were observed in the diaphragms of control animals or in the gastrocnemius muscle [15].

Thus, cytokines are constitutively expressed within the respiratory muscles, and are significantly upregulated during strenuous respiratory muscle contraction induced by inspiratory resistive loading. In fact, previous studies provide indirect evidence that cytokines are upregulated in the diaphragm, secondary to exercise [16]. When rats were subjected to an acute bout of exercise ( $90 \mathrm{~min}$ treadmill running) and their diaphragms were excised and homogenised at the end of the exercise session, the diaphragmatic homogenate could increase the in vitro proliferation of thymocytes, which suggested that increased cytokine bioactivity was present in the diaphragmatic homogenates, since cytokines are strong proliferative stimuli for thymocytes [16].

The upregulation of cytokine expression within the 

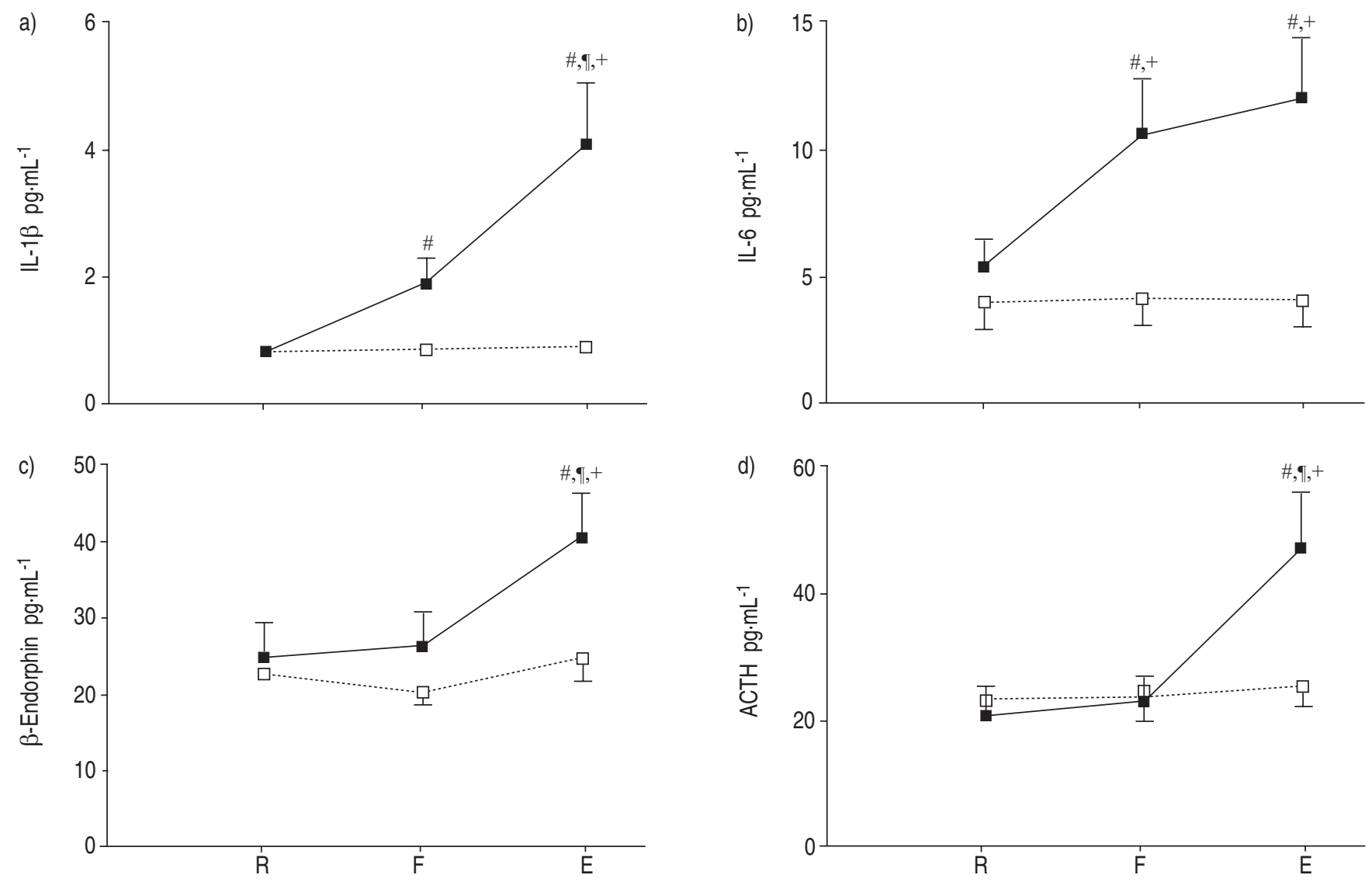

Fig. 2. - The plasma cytokine and hypothalamic pituitary responses to resistive breathing. Mean plasma level of interleukin (IL)-1 $\beta$ (a), IL-6 (b), $\beta$-endorphin (c) and adrenocorticotropin hormone (ACTH; d) at rest (R), at the point where the subjects could not generate the target maximum inspiratory pressure ( $75 \%$ of maximum, $45 \mathrm{~min}$ after the beginning of resistive breathing; $\mathrm{F}$ ), and at the end of resistive breathing (15 min later, at $60 \mathrm{~min}$ from the beginning; E). From F to E, subjects were put through an alinear resistance to the maximum they could achieve. Data are presented as mean \pm SEM. $\mathbf{~}$ : high-load run; $\square$ : moderate-load run. ${ }^{\#}$ : statistically significant difference $(\mathrm{p}<0.05)$ from R; ${ }^{\uparrow}$ : statistically significant difference $(\mathrm{p}<0.05)$ from $\mathrm{F}$; $^{+}$: statistically significant difference $(\mathrm{p}<0.01)$ from the moderate-load run. Modified from [5] with permission.

diaphragm, secondary to the resistive loading, observed represents relatively abundant mRNA tissue levels, since cytokines were detected using a multi-probe ribonuclease protection assay [15], which does not amplify the RNA signal and is less sensitive than the commonly used technique to detect RNA, the RT-PCR (requiring $10^{4}-10^{5}$ larger quantities for RNA to be present in the tissues for positive signal detection [17]). The mRNA upregulation was accompanied by commensurate increases in the cytokine protein levels, at least for the IL-6 and IL-1 $\beta$. Furthermore, immunohistochemistry revealed that myocytes are the IL-6-producing cells in the diaphragm.

It has to be acknowledged that the intradiaphragmatic cytokine production does not prove that these cytokines are released in the circulation and can account for the plasma cytokine elevation, secondary to resistive breathing. However, results from leg extension exercise studies, where the arteriovenous IL-6 difference across the contracting femoris muscle was determined, suggest that this is very likely, since the IL-6 production from the quadriceps femoris muscle could account for the systemic IL-6 elevation [18].

It can also be speculated that the increased transpulmonary pressure gradient during resistive breathing causes cytokine induction from cells that are resident in the lung, such as epithelial cells and fibroblasts, secondary to the augmented extraluminal stress imposed, which could contribute to the plasma cytokine elevation. This possibility is supported by studies of isolated, perfused mouse-lung preparations, where increased transpulmonary pressure led to IL-6 and TNF- $\alpha$ release [19]. It should be emphasised, however, that these results were obtained by profound overdistention of the lung, which is unlikely during resistive breathing, at least in normal humans and animals.

Consequently, the diaphragm is the only proven source of cytokine induction during resistive breathing. More studies are, of course, needed to elucidate other potential tissues/cells of cytokine origin, secondary to resistive loading.

It has to be acknowledged that the immune response described secondary to resistive breathing was observed in healthy humans and animals, and, thus, extrapolation of these results to disease states or other forms of loaded breathing (e.g. elastic loading) should be done with great caution. The level of loading was relatively high $(45-75 \%$ of maximum inspiratory pressure), which is usually observed during acute exacerbations of asthma or COPD leading to acute respiratory failure [20]. However, data from peripheral skeletal muscle exercise and the rat model of resistive breathing that the current authors used suggest that lower levels of resistive loading, if prolonged, would also lead to an immune response in a time-dependent fashion. Furthermore, when a skeletal muscle is "primed" by a bout of exercise, subsequent bouts of exercise (of equal duration and load) exhibit an augmented cytokine response [21]. Such a pattern would be typical of an asthmatic patient with waxing and waning airway narrowing. The underlying condition of the muscles and the adaptations observed secondary to disease states (e.g. COPD) might also influence the immune response 
to exercise. Although there is a paucity of existing data, the immune response to exercise is rather augmented in COPD patients [22]: only $11 \mathrm{~min}$ of cycling (at $40 \%$ of peak work rate) increased plasma TNF- $\alpha$ levels in COPD patients, but not in healthy controls. Obviously, more studies are needed to elucidate the immune response to resistive and other forms of loaded breathing in various disease states.

\section{The stimuli for the resistive breathing-induced plasma cytokines}

The stimulus for the upregulation of cytokine induction in response to resistive breathing is not known. Resistive breathing increases the production of reactive oxygen species (ROS), both within the working respiratory muscles and in the extracellular and vascular compartments [23]. ROS are able to induce cytokine production from various cell types. To test the hypothesis that oxidative stress is a stimulus for the cytokine induction secondary to resistive breathing, six healthy subjects performed two resistive breathing sessions before and after receiving a combination of antioxidants (vitamins E $200 \mathrm{mg} \cdot \mathrm{day}^{-1}$, A 50,000 IU $\cdot \mathrm{day}^{-1}$ and C $1,000 \mathrm{mg} \cdot \mathrm{day}^{-1}$ for $60 \mathrm{days}$, allopurinol $600 \mathrm{mg} \cdot \mathrm{day}^{-1}$ for 15 days and $N$-acetylcysteine $2 \mathrm{~g} \cdot \mathrm{day}^{-1}$ for 3 days before the second session) [6]. Before antioxidants, plasma cytokine levels (determined by ELISA) increased secondary to resistive breathing (TNF- $\alpha$ and IL- 6 by twofold, IL-1 $\beta$ by threefold). After antioxidants, plasma IL-1 $\beta$ became undetectable, the TNF- $\alpha$ response to resistive breathing was abolished, and the IL-6 response was significantly blunted (fig. 1) [6].

Since the diaphragmatic myocytes are the source of the resistive breathing-induced cytokines, the ability of ROS to stimulate the production of IL- 6 from skeletal myocytes was tested in vitro [24]. Differentiated $\mathrm{C} 2 \mathrm{C} 12$ murine skeletal muscle cells (myotubes) exposed to ROS-producing agents (pyrogallol, xanthine/xanthine oxidase or $\mathrm{H}_{2} \mathrm{O}_{2}$ ) for $24 \mathrm{~h}$ exhibited a concentration-dependent increase in IL-6 production. In addition, pre-treatment of cells with the ROS scavenger $N$-acetylcysteine blocked the TNF- $\alpha$-induced IL-6 release, suggesting a crucial role for endogenously produced ROS in IL-6 production, since TNF- $\alpha$ treatment leads to intracellular oxidative stress. Treatment of myocytes with ROS-generating agents increased nuclear factor (NF)- $\kappa \mathrm{B}$ dependent promoter activity. Finally, pre-incubation of myotubes with the pharmacological inhibitor of $\mathrm{NF}-\kappa \mathrm{B}$, diethyldithiocarbamate or transient transfection with a dominant negative NF- $\kappa \mathrm{B}$ construct inhibited the ROSstimulated IL-6 release. These in vitro results showed that ROS stimulate IL-6 production from skeletal muscle cells in a manner that involves transcriptional activation of the IL-6 gene via a NF- $\kappa \mathrm{B}$-dependent pathway [24].

The antioxidant supplementation blunted, but did not completely abolish the IL-6 response to resistive breathing. This suggests that the stimuli for the IL- 6 production during resistive breathing might be multiple. Although these stimuli during resistive breathing have not been studied, results from whole-body exercise studies suggest that carbohydrates attenuate the IL-6 response to exercise and glycogen depletion greatly augments it [25]. Interestingly, significant glycogen depletion has been documented in the diaphragm secondary to resistive breathing [26]. Furthermore, adrenergic stimulation could also have a contributing role [25].

The stimuli for the induction of cytokines other than IL-6 during exercise are less well studied. Pre-treatment with antioxidants abolished the resistive breathing-induced elevation of TNF- $\alpha$, whereas IL-1 $\beta$ became undetectable (fig. 1) [6], which suggests that oxidative stress is a strong stimulus for the resistive breathing-induced IL- $1 \beta$ and $\mathrm{TNF}-\alpha$ response.

Thus, it is possible that the plasma cytokine induction during resistive breathing is differentially regulated by various stimuli, some of them being common (e.g. ROS), whose relative importance varies with each respective cytokine. Further studies are needed to elucidate other potential stimuli for the resistive breathing-induced cytokine upregulation.

\section{Implications for respiratory failure}

Resistive breathing-induced cytokine upregulation may serve several local and systemic functions, which could be both adaptive and maladaptive.

\section{Local effects}

Muscle injury. Strenuous resistive breathing results in diaphragmatic injury in both animals and humans [2, 3, 27]. The mechanisms involved are not definitely established, though increased activity of the proteolytic enzymes' calpains [2] and ROS [27] are involved. It is tempting to speculate that intradiaphragmatic cytokine induction could be involved in mediating the injurious process [15]. In fact, cytokines, such as IL-1 $\beta$, can upregulate the expression of adhesion molecules on the surface of endothelial cells and enhance transendothelial migration of blood-derived inflammatory cells [28]. Initially, this would recruit neutrophils and, later, monocytes within the muscle, which might mediate the injury. This response is similar to the eccentric exercise-induced intramuscular IL-1 expression and neutrophilic infiltration associated with limb muscle damage in humans [29]. Furthermore, cytokines, such as TNF- $\alpha$, could augment oxidative stress in a paracrine fashion [30], which could contribute to muscle injury [27]. In fact, increased oxidative stress was documented in the diaphragm even 3 days after resistive loading [27], which cannot be attributed to increased muscle activation at that time point ( 3 days after activity). Cytokines and cytokine receptors are upregulated in the muscles in various forms of muscle injury [31], and in muscle diseases, such as critical illness polyneuropathy and myopathy [32]. However, the cytokine response is not only maladaptive. In fact, not only pro-inflammatory cytokines, such as IL- $1 \beta$, TNF- $\alpha$ and IFN- $\gamma$, were induced, but antiinflammatory cytokines, such as IL-4, IL-10 and IL-6 (which has some pro- but mainly anti-inflammatory properties [33]), were also upregulated [15], suggesting that some of these cytokines might serve to control local inflammation [33].

Muscle regeneration. Cytokines are also essential in orchestrating muscle recovery after injury. Cytokines, such as TNF- $\alpha$, IL-6, leukaemia inhibitory factor and IL-1 $\beta[31$, 34-36], and their cognate receptors [37] are upregulated in skeletal muscle after injury. These cytokines enhance proteolytic removal of damaged proteins [38, 39] and cells (via recruitment and activation of phagocytes). TNF- $\alpha$ also activates satellite cells to enter the cell cycle from the normally quiescent state and enhances their proliferation once it has been initiated [40]. Satellite cells are quiescent cells of embryonic origin that reside in the muscle and are transformed into myocytes either during the normal muscle remodelling or when the muscle becomes injured to replace damaged myocytes [41].

Muscle contractility. Cytokines might affect contractility of the diaphragm. TNF- $\alpha$ impairs the in vitro contractility of 

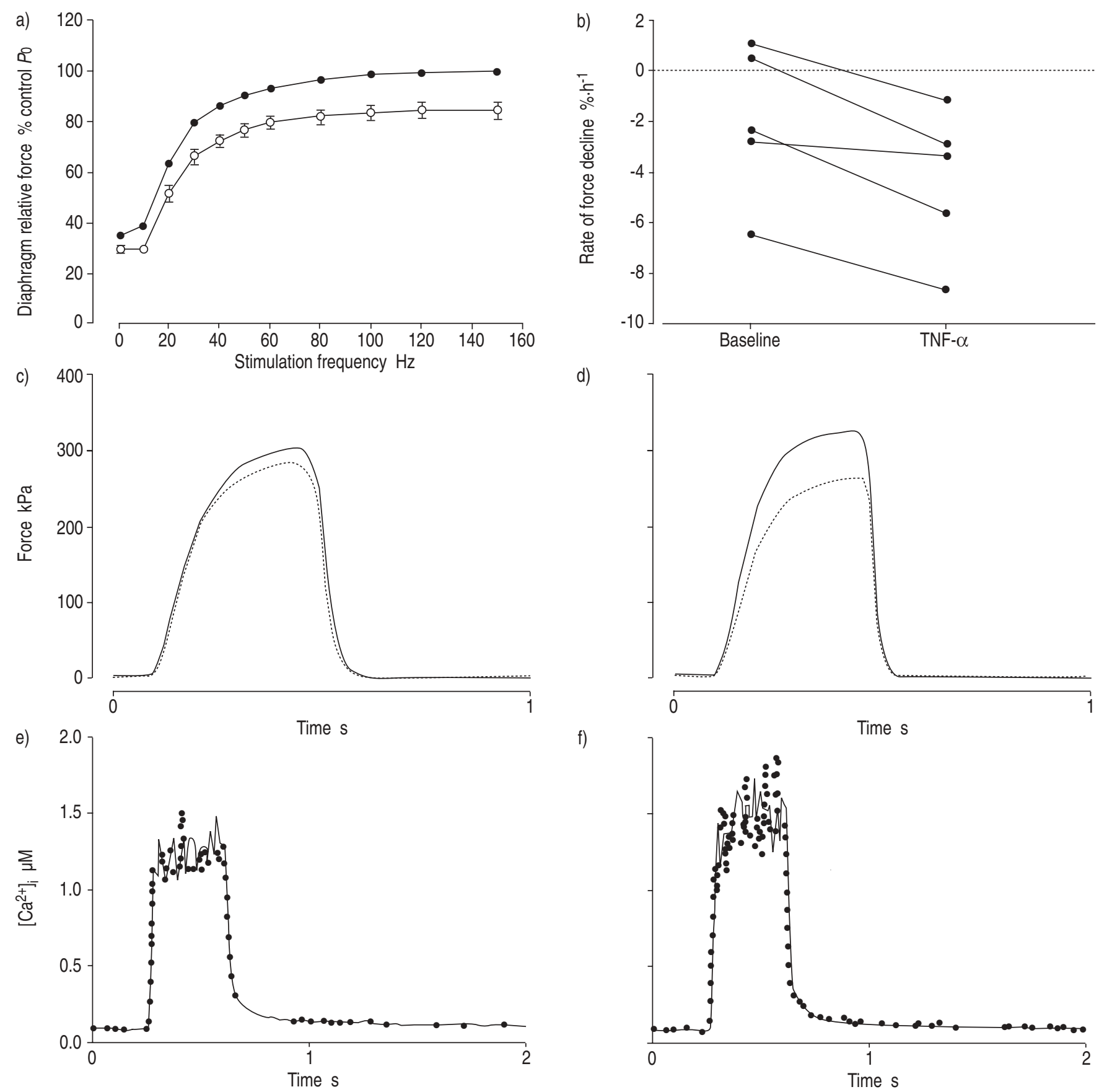

f)

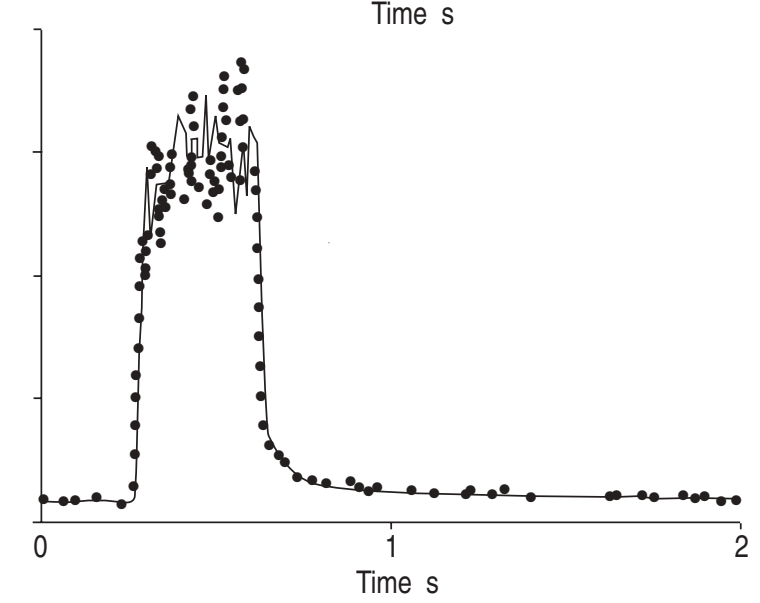

Fig. 3. - Effect of tumour necrosis factor (TNF)- $\alpha$ on diaphragmatic contractility. a) TNF- $\alpha$ depresses diaphragm force. Diaphragm fibre bundles treated with TNF- $\alpha 500 \mathrm{ng} \cdot \mathrm{mL}^{-1}(\bigcirc)$ developed lower forces than paired controls $(\bullet)$ at all stimulus frequencies $(\mathrm{p}<0.001)$. Data are presented as mean \pm SEM. P0: maximal tetanic force. $n=8$ per group. b) TNF- $\alpha$ stimulates loss of force in single fibres. Values depict mean rates of force decline $\left(\% \cdot \mathrm{h}^{-1}\right)$ measured by regression analysis using data from individual experimental fibres $(\mathrm{n}=5)$ before and after exposure to TNF- $\alpha$ $500 \mathrm{ng} \cdot \mathrm{mL}^{-1}$. TNF- $\alpha$ accelerated the loss of force in each of five fibres studied $(\mathrm{p}<0.02)$. c, d) Depression of tetanic force transients by TNF- $\alpha$. Individual tracings obtained from intact single fibres stimulated at $80 \mathrm{~Hz}$ before $(-)$ and after (......) 4-h incubation in either buffer alone (control fibre; c) or in TNF- $\alpha 500 \mathrm{ng} \cdot \mathrm{mL}^{-1}$ (experimental fibre; d). e, f) Insensitivity of tetanic intracellular calcium ion concentration ([Ca $\left.{ }^{2+}\right]_{\mathrm{i}}$ ) transients to TNF- $\alpha$. Individual tracings obtained from intact single fibres stimulated at $80 \mathrm{~Hz}$ before $(\longrightarrow)$ and after $(\bullet)$ 4-h incubation in either buffer alone (control fibre; e) or in TNF- $\alpha 500 \mathrm{ng} \cdot \mathrm{mL}^{-1}$ (experimental fibre; f). Modified from [43] with permission.

diaphragm strips from hamsters [42], mice (fig. 3a) [43], or intact diaphragmatic muscle fibres from mice (fig. 3b) [43]. Diaphragm strips from mice exhibiting cardiac overexpression of TNF- $\alpha$ with resultant high circulating TNF- $\alpha$ levels show contractile dysfunction of the diaphragm [44], and $i$. v. TNF- $\alpha$ administration depressed the in vivo contractility of the diaphragms of dogs [45]. The mechanism by which TNF- $\alpha$ depresses diaphragmatic contractility is not definitely established. However, the effect is at the level of the myofibrils (actin and myosin) (fig. $3 \mathrm{c}$ and d), since the calcium release and re-uptake is not affected (fig. $3 \mathrm{e}$ and $\mathrm{f}$ ) [43]. The intradiaphragmatic expression of cytokines and, especially, TNF- $\alpha$ with the attendant contractility-depressing effect might contribute to the development of peripheral muscle fatigue (i.e. decreased force production upon constant electrical stimulation of the muscle) observed after resistive 
loading [1]. The intradiaphragmatic expression of cytokines and, especially, TNF- $\alpha$ might also explain the observation that force decline after resistive loading is proportionally greater than the observed muscle injury [46]. Whereas force declines by as much as $30 \%$, the degree of injury is only $9 \%$, which suggests that other factors, in addition to injury, are depressing the contractility of the diaphragm [46].

\section{Systemic effects}

Cytokines produced within the diaphragm secondary to resistive breathing may spill into the circulation, thus explaining the cytokinemia observed after resistive loading in normal humans $[5,6]$. Interestingly, in diseases of increased diaphragmatic loading, such as COPD, increased plasma cytokine levels have been documented [47-50]. Although, initially, these cytokines had been attributed to the bronchial inflammation that accompanies COPD, recent data have shown different regulation of the cytokine response in induced sputum and plasma [47], which suggests that plasma cytokinemia in COPD is not due to an overflow of inflammatory mediators from the local lung compartment. It is tempting to speculate that cytokines produced within the diaphragm, secondary to the increased load, enter the circulation and could explain the discrepancies between the lung and systemic inflammation. Interestingly, plasma IL-6 was increased during an exacerbation of COPD [51], a condition that further augments the load faced by the respiratory muscles. Furthermore, COPD patients exhibit an augmented plasma $\mathrm{TNF}-\alpha$ response to exercise, which cannot be attributed to production of TNF- $\alpha$ by the exercising leg muscles, since no increase was observed in the TNF- $\alpha$ mRNA level in biopsy samples from the vastus lateralis muscles of these patients [22]. An interesting, yet speculative explanation could be that TNF- $\alpha$ can originate from the strenuously contracting respiratory muscles of COPD patients during exercise.

Increased plasma IL- 6 and TNF- $\alpha$ levels have also been documented in sleep apnoea patients [52-55], which could not be explained by the attendant obesity, since obese individuals with similar body mass indices had significantly lower cytokine values. A potential explanation could be that cytokines are produced by the diaphragm, secondary to the strenuous contractions induced by upper airway obstructions during apnoeas and hypopnoeas. Along these lines, a significant elevation of TNF- $\alpha$ and a smaller (nonstatistically significant) elevation of IL-6 were observed during sleep after the first obstructive apnoea [55]. Hypoxaemia that developed during sleep, secondary to the apnoeas-hypopnoeas, might also contribute to the plasma cytokine elevation [55]. In fact, the effects of exercise and hypoxaemia are synergistic in elevating plasma IL-6 [56]. In support of the role of strenuous respiratory muscle contraction and hypoxaemia as the reasons for cytokine elevation in sleep apnoea, nasal continuous positive airway pressure therapy, which prevents the apnoeas-hypopnoeas with the attendant strenuous diaphragmatic contractions and the episodes of hypoxaemia, results in significant decrease of plasma IL-6 levels [54]. Furthermore, a deranged ex vivo production of TNF- $\alpha$ is observed in sleep apnoea patients [57], where the nocturnal elevation of the ex vivo production of TNF- $\alpha$ by blood mononuclear cells stimulated in vitro by lipopolysaccharide (endotoxin) is blunted. This pattern is quite similar to what is happening in normal subjects during exercise; while plasma cytokines increase secondary to the exercise, when blood mononuclear cells derived from the same subjects are stimulated in vitro, the ex vivo production of cytokines by these cells is downregulated after exercise [58]. In sleep apnoea patients, plasma cytokines increase during the night, while the production of cytokines by blood mononuclear cells stimulated in vitro decreases [57], suggesting that the immune response to sleep apnoea might, in essence, be an immune response to the "exercise" imposed to the respiratory muscles by the repeated episodes of apnoeas-hypopnoeas. Further studies are needed to elucidate these interesting possibilities.

The circulating resistive breathing-induced cytokines may serve several functions, as follows.

Effects on metabolism and endurance. The significantly greater induction of IL-6 within the diaphragm, secondary to resistive breathing, suggests that it might be involved in physiological muscle signalling, and not only to the injury-inflammation repair process [25]. Diaphragmatic contraction leads to glycogen depletion [26], which greatly augments IL-6 production from skeletal muscles [14, 59]. IL-6 has a hormone-like glucoregulatory role, signalling that glycogen stores are reaching critically low levels in the contracting muscles, and stimulating hepatic glucose output to maintain glucose homeostasis and muscle glucose supply [25]. IL-6 also augments lipolysis and fat oxidation [60], which increases the energy that is available to the "exercising" respiratory muscles. IL-6 overproduction might be required for protecting the endurance of the respiratory muscles in conditions of increased respiratory load. Accordingly, double IL-6 knockout mice (IL-6-/-) [61] exhibit reduced endurance to exercise compared with control mice, which suggests that endogenously produced IL-6 is important for maintenance of exercise capacity. IL- 6 could serve to attenuate the TNF- $\alpha$ induction, secondary to exercise [62], which decreases diaphragm contractility. Thus, the greater induction of IL-6 within the diaphragm, secondary to resistive breathing, might represent an adaptive response to augment diaphragmatic endurance and contractility in the face of increased load.

Cachexia. Cytokines may contribute to the cachexia observed in some COPD patients [63-65]. In fact, a reduced creatinine height index (an indirect measure of skeletal muscle mass) was associated with increased circulating levels of IL-6, TNF- $\alpha$ and their soluble receptors [48]. The interested reader could consult recent excellent reviews [63, 64].

Sleep. Diaphragm-derived cytokines may also have central nervous system effects. Both TNF- $\alpha$ and IL- $1 \beta$ affect sleep in healthy and diseased states. The interested reader could consult a recent review [66].

Hypothalamic pituitary adrenal axis stimulation. Cytokines, and especially IL-1 $\beta$ and IL-6, are very strong stimulants of the hypothalamic-pituitary-adrenal (HPA) axis [67-69] (fig. 4), exhibiting significant synergism [70]. Both stimulate hypothalamic corticotrophin-releasing hormone secretion from parvicellular neurons located in the paraventricular nuclei, which is the major pro-opiomelanocortin secretagogue by the pituitary corticotroph $[67,70]$. The pro-opiomelanocortin molecule is then subjected to post-translational modification to produce adrenocorticotropin (ACTH) and $\beta$-endorphin, which are concomitantly secreted by the pituitary gland. In fact, cytokines, such as TNF- $\alpha$, IL-1 or IL-6, exhibit significant synergism in stimulating the release of ACTH [71]. IL-6 plays a fundamental role in the stimulation of the HPA axis, but the participation and interaction of IL- 1 and TNF- $\alpha$ is also required [70]. Interestingly, strenuous inspiratory resistive breathing that induces plasma cytokines stimulates the HPA axis, resulting in increased levels of circulating $\beta$-endorphin and ACTH [5] (fig. 2).

There are two alternative, not mutually exclusive explanations 

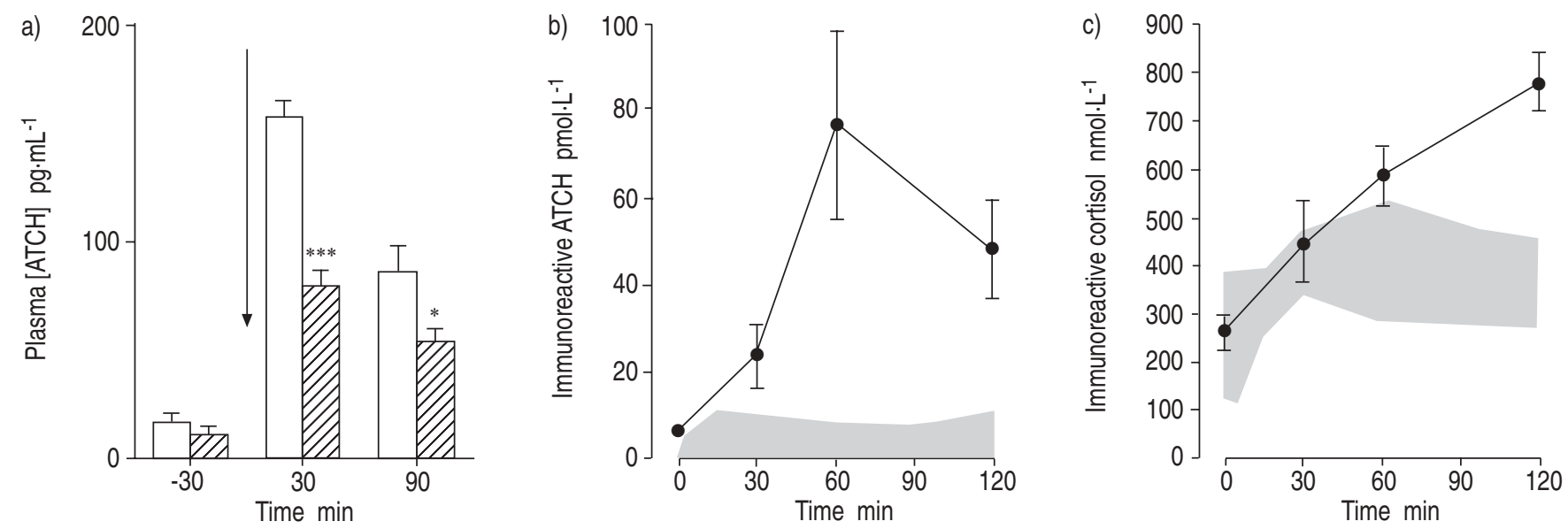

Fig. 4. - Cytokines stimulate the hypothalamic pituitary adrenal axis. a) Changes in plasma concentration of adrenocorticotropin ([ACTH]) in capsaicin-desensitised ( $\mathbb{Z} ; \mathrm{n}=6)$ and control $(\square ; \mathrm{n}=6)$ groups after i.v. injection of interleukin (IL)-1 $\beta\left(2 \mu \mathrm{g} \cdot \mathrm{kg}^{-1} ;\right.$ arrow). $*: \mathrm{p}<0.05 ; * * *: \mathrm{p}<0.001$. Modified from [68] with permission. Plasma immunoreactive ACTH (b) and cortisol (c) responses to a s.c. bolus injection of IL-6 (30 $\mu \mathrm{g} \cdot \mathrm{kg}^{-1}$ ). The grey areas represent the mean \pm SD responses of healthy normal volunteers to a standard bolus dose $\left(1 \mu \mathrm{g} \cdot \mathrm{kg}^{-1}\right)$ of corticotrophin-releasing hormone and were included for comparison. Modified from [69] with permission.

for the mechanism of HPA activation, secondary to resistive breathing. First, it may have resulted secondary to the increased levels in circulating proinflammatory cytokines induced by strenuous resistive breathing. This notion is supported by the different time courses of cytokine and hormonal elevations (cytokine elevation appearing first, followed by the increase in $\beta$-endorphin and ACTH level; fig. 2). Furthermore, the increase in IL-6 was strongly correlated with the increase in both $\beta$-endorphin and ACTH, implying a causative role of IL- 6 for the HPA-axis stimulation, secondary to resistive breathing (fig. 4). A second alternative/complementary mechanism accounting for the increased levels of $\beta$-endorphin and ACTH is that they may be due to stimulation of small afferent nerve fibres (type III and IV). In fact, it has been suggested that small-diameter phrenic afferent fibres are stimulated by strenuous contraction-induced metabolic changes in the diaphragm, and that these fibres project to various levels of the central nervous system [72]. Therefore, it is tempting to speculate that strenuous inspiratory resistive breathing causes $\beta$-endorphin and ACTH secretion, secondary to stimulation of small afferent nerve fibres, within the respiratory muscles [68]. In fact, this might also be due to the effect of intradiaphragmatically produced cytokines, since cytokines can stimulate small afferent nerve fibres, leading to ACTH elevation [68, 70].

The ACTH response may represent an attempt of the organism to reduce the injury occurring in the respiratory muscles via the production of glucocorticoids by the adrenals, which suppress inflammatory genes, and induction of the acute phase-response proteins from the liver, which serve as antiproteases [67].

Control of breathing. Diaphragm-derived cytokines may also affect the control of breathing. In fact, large exogenous doses of IL-1 $\beta$ [73] and endotoxin, which leads to pro-inflammatory cytokine release [74], stimulate the respiratory controller. However, the effect of endogenously produced cytokines might be different. This could either be a direct effect on the respiratory controller or an indirect effect mediated through the production of $\beta$-endorphins, though the two mechanisms might coexist. Accordingly, mice suffering from muscular dystrophy have blunted ventilatory response to hypercapnic challenge $\left(\begin{array}{llll}7 \% & \mathrm{CO}_{2}\end{array}\right)$ compared with normal mice [75]. Concurrent elimination of TNF- $\alpha$ (by deletion of the genes for TNF- $\alpha$ ) significantly improved the hypercapnic ventilatory response, which suggests that endogenously produced TNF- $\alpha$ depresses the respiratory controller [75].

The indirect effect is likely to be mediated through the elaboration of $\beta$-endorphins that decrease the activation of the respiratory muscles and change the pattern of breathing, which becomes rapid and shallow. This is probably an attempt of the respiratory controller to reduce the strenuous respiratory muscle contractions and, thus, the accompanying muscle injury, through the decline in tidal volume at the expense of increased respiratory frequency [76]. In animals, adequate evidence supports this concept [77-80]. It was demonstrated that resistive loading resulted in a progressive reduction in tidal volume, which was partially reversed by administration of the opioid antagonist naloxone $[76,79]$ (fig. 5). An increase in $\beta$-endorphin in the cisternal cerebrospinal fluid was also detected [79].

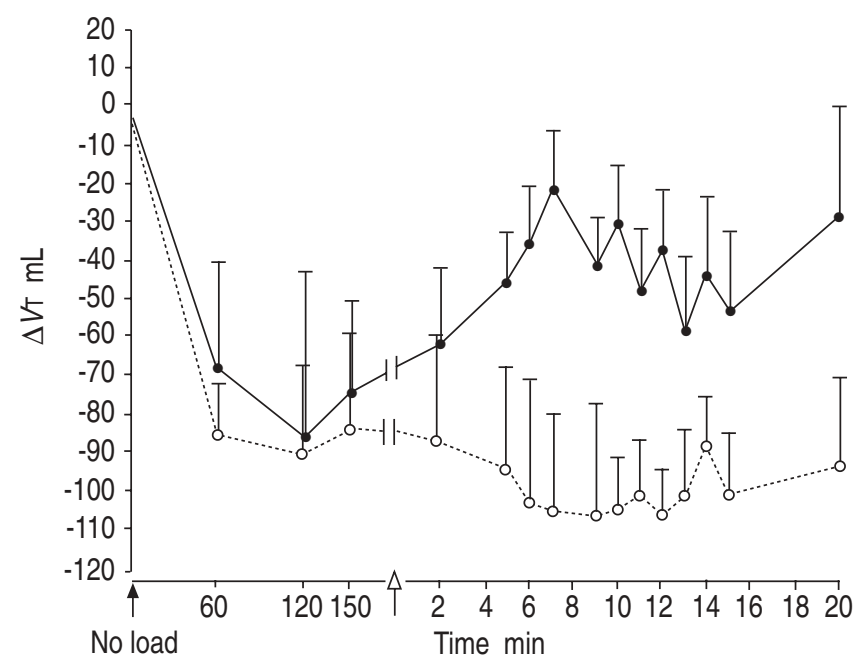

Fig. 5. - Endorphins and resistive loading. The tidal volume $(V \mathrm{~T})$ response of unanaesthetised goats to $2.5 \mathrm{~h}$ of high inspiratory flowresistive loading prior to and following the administration (open arrow) of naloxone $(\bullet)$ or saline $(\bigcirc)$. $V \mathrm{~T}$, which fell considerably after loading (shallow breathing), increased after naloxone administration, while saline had no effect. These data indicate that inspiratory resistive loading activates the endogenous opioid system, and that the reduction of $V_{\mathrm{T}}$ in response to loading is partly mediated by $\beta$ endorphins. Data are presented as mean \pm SEM. Modified from [76] with permission. 


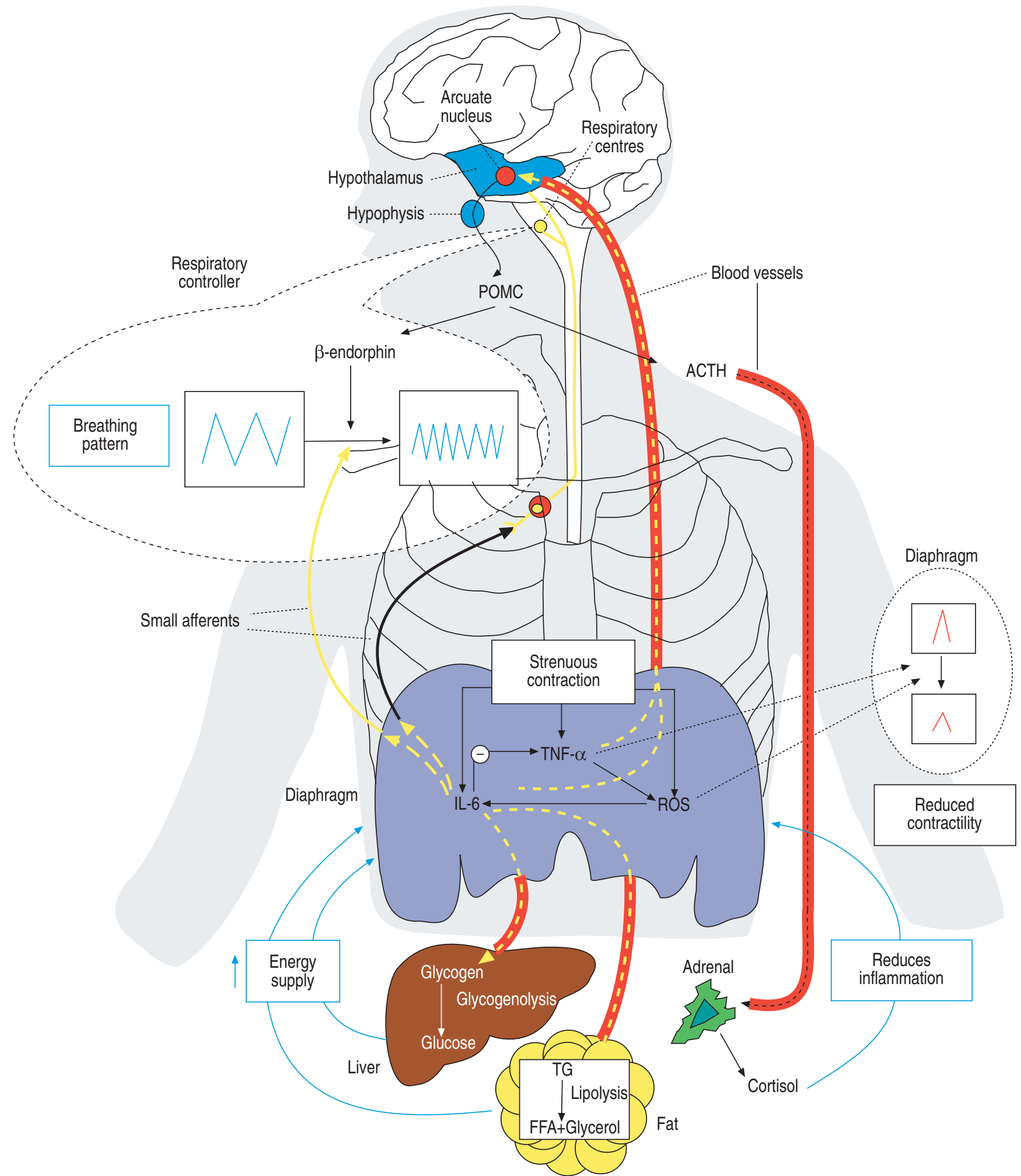

Fig. 6. - Integrated view of the origin and functional consequences of resistive breathing-induced cytokines. Resistive breathing results in the generation of oxidative stress and the induction of cytokines within the diaphragm, secondary to the increased muscle activation. Oxidative stress is a major stimulus for this cytokine induction. Tumour necrosis factor (TNF)- $\alpha$ compromises diaphragmatic contractility and contributes to the development of muscle cachexia. Interleukin (IL)- 6 attenuates the TNF- $\alpha$ expression, secondary to strenuous diaphragmatic contraction. IL-6 mobilises glucose from the liver and free fatty acid (FFA) from the adipose tissue, which increases the energy available to the strenuously working respiratory muscles. At the same time, cytokines stimulate the hypothalamic-pituitary-adrenal axis either haematogenously or via stimulation of small afferent nerve fibres, leading to production of adrenocorticotropin (ACTH) and $\beta$-endorphins. The ACTH response may represent an attempt of the organism to reduce the injury occurring in the respiratory muscles through the production of glucocorticoids by the adrenals and the induction of the acute phase-response proteins. The $\beta$-endorphin response would decrease the activation of the respiratory muscles and change the pattern of breathing, which becomes more rapid and shallow, possibly in an attempt to reduce and/or prevent further injury to the respiratory muscles. POMC: pro-opiomelaninocortin; ROS: reactive oxygen species; TG: triglycerides. 
In humans, in support of the role of $\beta$-endorphins, an increase in the $\beta$-endorphin plasma level was measured, secondary to resistive breathing $[5,81]$. It was also demonstrated that naloxone could restore the load-compensatory reflex in patients with COPD in whom it was initially absent [82]. In 14 patients with COPD (but without respiratory failure) and eight normal controls, ventilation, mechanical lung function, respiratory sensitivity to carbon dioxide, and the increase in respiratory effort elicited by an increase in resistance to breathing were measured before and after administration of naloxone. Before naloxone, increased resistance to breathing enhanced respiratory effort in all controls, but seven out of 14 patients with COPD had no response. After naloxone, these seven patients had load responses. Furthermore, the respiratory effort elicited by the resistance also increased after the drug was given to the patients who had had a response [82]. Moreover, in asthmatics after methacholine challenge inducing severe reductions in forced expiratory volume in one second, pretreatment naloxone resulted in increased occlusion pressure and mean inspiratory flow rate (two measures of the respiratory drive) when compared with saline pre-treatment [83], which suggested that during metacholine-induced resistive loading, endorphins were suppressing the drive of the respiratory controller to the respiratory muscles, which was augmented after pre-treatment naloxone.

Such a strategy, representing an adaptive response much in the way that $\beta$-endorphins are generated in response to chronic pain, certainly minimises dyspnoea and may avoid or delay the onset of respiratory muscle peripheral fatigue, protecting the ventilatory pump from exhaustion. However, it may result in hypoventilation and development of hypercapnia.

Summary. Figure 6 illustrates an integrated view of the origin and functional consequences of resistive breathing-induced cytokines. Resistive breathing results in the generation of oxidative stress and the induction of cytokines within the diaphragm, secondary to the increased muscle activation. Oxidative stress is a major stimulus for this cytokine induction. TNF- $\alpha$ compromises diaphragmatic contractility and contributes to the development of muscle cachexia. IL-6 attenuates the TNF- $\alpha$ expression, secondary to strenuous diaphragmatic contraction. IL-6 mobilises glucose from the liver and free fatty acid from the adipose tissue, which increases the energy available to the strenuously working respiratory muscles.

At the same time, cytokines stimulate the hypothalamicpituitary-adrenal axis either haematogenously or via stimulation of small afferent nerve fibres, leading to production of adrenocorticotropin and $\beta$-endorphins. The adrenocorticotropin response may represent an attempt of the organism to reduce the injury occurring in the respiratory muscles through the production of glucocorticoids by the adrenals and the induction of the acute phase-response proteins. The $\beta$ endorphin response would decrease the activation of the respiratory muscles and change the pattern of breathing, which becomes more rapid and shallow, possibly in an attempt to reduce and/or prevent further injury to the respiratory muscles.

\section{References}

1. Roussos CS, Macklem PT. Diaphragmatic fatigue in man. J Appl Physiol 1977; 43: 189-197.

2. Reid WD, Belcastro AN. Time course of diaphragm injury and calpain activity during resistive loading. Am J Respir Crit Care Med 2000; 162: 1801-1806.

3. Orozco-Levi M, Lloreta J, Minguella J, Serrano S, Broquetas
JM, Gea J. Injury of the human diaphragm associated with exertion and chronic obstructive pulmonary disease. Am J Respir Crit Care Med 2001; 164: 1734-1739.

4. Pedersen BK, Hoffman-Goetz L. Exercise and the immune system: regulation, integration, and adaptation. Physiol Rev 2000; 80: 1055-1081.

5. Vassilakopoulos T, Zakynthinos S, Roussos C. Strenuous resistive breathing induces proinflammatory cytokines and stimulates the HPA axis in humans. Am J Physiol 1999; 277: R1013-R1019.

6. Vassilakopoulos T, Katsaounou P, Karatza MH, Kollintza A, Zakynthinos S, Roussos C. Strenuous resistive breathing induces plasma cytokines: role of antioxidants and monocytes. Am J Respir Crit Care Med 2002; 166: 1572-1578.

7. Katsaounou P, Karatza MH, Kollintza A, et al. The immune response to strenuous resistive breathing (abstract). Am J Respir Crit Care Med 2001; 163: A621.

8. van Furth R. Human monocytes and cytokines. Res Immunol 1998; 149: 719-720.

9. Bosenberg AT, Brock-Utne JG, Gaffin SL, Wells MT, Blake GT. Strenuous exercise causes systemic endotoxemia. J Appl Physiol 1988; 65: 106-108.

10. Steppich B, Dayyani F, Gruber R, Lorenz R, Mack M, Ziegler-Heitbrock HW. Selective mobilization of CD14(+)CD16(+) monocytes by exercise. Am J Physiol Cell Physiol 2000; 279: C578-C586.

11. Prussin C. Cytokine flow cytometry: understanding cytokine biology at the single-cell level. J Clin Immunol 1997; 17: 195204.

12. Saghizadeh M, Ong JM, Garvey WT, Henry RR, Kern PA. The expression of TNF alpha by human muscle. Relationship to insulin resistance. J Clin Invest 1996; 97: 1111-1116.

13. Belec L, Authier FJ, Chazaud B, Piedouillet C, BarlovatzMeimon G, Gherardi RK. Interleukin (IL)-1 beta and IL-1 beta mRNA expression in normal and diseased skeletal muscle assessed by immunocytochemistry, immunoblotting and reverse transcriptase-nested polymerase chain reaction. J Neuropathol Exp Neurol 1997; 56: 651-663.

14. Keller C, Steensberg A, Pilegaard H, et al. Transcriptional activation of the IL- 6 gene in human contracting skeletal muscle: influence of muscle glycogen content. FASEB J 2001; 15: 2748-2750.

15. Vassilakopoulos T, Divangahi M, Rallis G, et al. Differential cytokine gene expression in the diaphragm in response to strenuous resistive breathing. Am J Respir Crit Care Med 2004; 170: 154-161.

16. Oh-ishi S, Kizaki T, Ookawara T, et al. Endurance training improves the resistance of rat diaphragm to exercise-induced oxidative stress. Am J Respir Crit Care Med 1997; 156: 15791585.

17. Wang T, Brown MJ. mRNA quantification by real time TaqMan polymerase chain reaction: validation and comparison with RNase protection. Anal Biochem 1999; 269: 198201.

18. Steensberg A, van Hall G, Osada T, Sacchetti M, Saltin B, Klarlund PB. Production of interleukin-6 in contracting human skeletal muscles can account for the exercise-induced increase in plasma interleukin-6. J Physiol 2000; 529: 237242.

19. von Bethmann AN, Brasch F, Nusing R, et al. Hyperventilation induces release of cytokines from perfused mouse lung. Am J Respir Crit Care Med 1998; 157: 263-272.

20. Zakynthinos SG, Vassilakopoulos T, Roussos C. The load of inspiratory muscles in patients needing mechanical ventilation. Am J Respir Crit Care Med 1995; 152: 1248-1255.

21. Ronsen O, Lea T, Bahr R, Pedersen BK. Enhanced plasma IL-6 and IL-1ra responses to repeated versus single bouts of prolonged cycling in elite athletes. J Appl Physiol 2002; 92: 2547-2553.

22. Rabinovich RA, Figueras M, Ardite E, et al. Increased tumour necrosis factor-alpha plasma levels during moderate-intensity exercise in COPD patients. Eur Respir J 2003; 21: 789-794. 
23. Reid MB. Invited review: redox modulation of skeletal muscle contraction: what we know and what we don't. J Appl Physiol 2001; 90: 724-731.

24. Kosmidou I, Vassilakopoulos T, Xagorari A, Zakynthinos S, Papapetropoulos A, Roussos C. Production of interleukin-6 by skeletal myotubes: role of reactive oxygen species. $\mathrm{Am} \mathrm{J}$ Respir Cell Mol Biol 2002; 26: 587-593.

25. Pedersen BK, Steensberg A, Schjerling P. Muscle-derived interleukin-6: possible biological effects. $J$ Physiol 2001; 536: 329-337.

26. Ciufo R, Dimarco A, Stofan D, Nethery D, Supinski G. Dichloroacetate reduces diaphragmatic lactate formation but impairs respiratory performance. Am J Respir Crit Care Med 2001; 164: 1669-1674.

27. Jiang TX, Darlene RW, Road JD. Free radical scavengers and diaphragm injury following inspiratory resistive loading. Am J Respir Crit Care Med 2001; 164: 1288-1294.

28. Cannon JG, St Pierre BA. Cytokines in exertion-induced skeletal muscle injury. Mol Cell Biochem 1998; 179: 159-167.

29. Fielding RA, Manfredi TJ, Ding W, Fiatarone MA, Evans WJ, Cannon JG. Acute phase response in exercise. III. Neutrophil and IL-1 beta accumulation in skeletal muscle. Am J Physiol 1993; 265: R166-R172.

30. Reid MB, Li YP. Cytokines and oxidative signalling in skeletal muscle. Acta Physiol Scand 2001; 171: 225-232.

31. Warren GL, Hulderman T, Jensen N, et al. Physiological role of tumour necrosis factor alpha in traumatic muscle injury. FASEB J 2002; 16: 1630-1632.

32. De Letter MA, van Doorn PA, Savelkoul HF, et al. Critical illness polyneuropathy and myopathy (CIPNM): evidence for local immune activation by cytokine-expression in the muscle tissue. J Neuroimmunol 2000; 106: 206-213.

33. Xing Z, Gauldie J, Cox G, et al. IL-6 is an antiinflammatory cytokine required for controlling local or systemic acute inflammatory responses. J Clin Invest 1998; 101: 311-320.

34. Kami K, Senba E. Localization of leukemia inhibitory factor and interleukin-6 messenger ribonucleic acids in regenerating rat skeletal muscle. Muscle Nerve 1998; 21: 819-822.

35. Kurek JB, Nouri S, Kannourakis G, Murphy M, Austin L. Leukemia inhibitory factor and interleukin- 6 are produced by diseased and regenerating skeletal muscle. Muscle Nerve 1996; 19: 1291-1301.

36. Cannon JG, Fielding RA, Fiatarone MA, Orencole SF, Dinarello CA, Evans WJ. Increased interleukin 1 beta in human skeletal muscle after exercise. Am J Physiol 1989; 257: R451-R455.

37. Kami K, Morikawa Y, Sekimoto M, Senba E. Gene expression of receptors for IL-6, LIF, and CNTF in regenerating skeletal muscles. J Histochem Cytochem 2000; 48: 1203-1213.

38. Llovera M, Carbo N, Lopez-Soriano J, et al. Different cytokines modulate ubiquitin gene expression in rat skeletal muscle. Cancer Lett 1998; 133: 83-87.

39. Tsujinaka T, Kishibuchi M, Yano M, et al. Involvement of interleukin-6 in activation of lysosomal cathepsin and atrophy of muscle fibers induced by intramuscular injection of turpentine oil in mice. J Biochem (Tokyo) 1997; 122: 595600 .

40. Li YP. TNF-alpha is a mitogen in skeletal muscle. $A m J$ Physiol Cell Physiol 2003; 285: C370-C376.

41. Hawke TJ, Garry DJ. Myogenic satellite cells: physiology to molecular biology. J Appl Physiol 2001; 91: 534-551.

42. Wilcox P, Milliken C, Bressler B. High-dose tumour necrosis factor alpha produces an impairment of hamster diaphragm contractility. Attenuation with a prostaglandin inhibitor. Am J Respir Crit Care Med 1996; 153: 1611-1615.

43. Reid MB, Lannergren J, Westerblad H. Respiratory and limb muscle weakness induced by tumour necrosis factoralpha: involvement of muscle myofilaments. Am J Respir Crit Care Med 2002; 166: 479-484.

44. Li X, Moody MR, Engel D, et al. Cardiac-specific overexpression of tumour necrosis factor-alpha causes oxidative stress and contractile dysfunction in mouse diaphragm. Circulation 2000; 102: 1690-1696.

45. Wilcox PG, Wakai Y, Walley KR, Cooper DJ, Road J. Tumour necrosis factor alpha decreases in vivo diaphragm contractility in dogs. Am J Respir Crit Care Med 1994; 150: $1368-1373$.

46. Jiang TX, Reid WD, Road JD. Delayed diaphragm injury and diaphragm force production. Am J Respir Crit Care Med 1998; 157: 736-742.

47. Vernooy JH, Kucukaycan M, Jacobs JA, et al. Local and systemic inflammation in patients with chronic obstructive pulmonary disease: soluble tumour necrosis factor receptors are increased in sputum. Am J Respir Crit Care Med 2002; 166: $1218-1224$

48. Eid AA, Ionescu AA, Nixon LS, et al. Inflammatory response and body composition in chronic obstructive pulmonary disease. Am J Respir Crit Care Med 2001; 164 : 1414-1418.

49. Godoy I, Campana AO, Geraldo RR, Padovani CR, Paiva SA. Cytokines and dietary energy restriction in stable chronic obstructive pulmonary disease patients. Eur Respir $J$ 2003; 22: 920-925.

50. Koechlin C, Couillard A, Cristol JP, et al. Does systemic inflammation trigger local exercise-induced oxidative stress in COPD? Eur Respir $J$ 2004; 23: 538-544.

51. Wedzicha JA, Seemungal TA, MacCallum PK, et al. Acute exacerbations of chronic obstructive pulmonary disease are accompanied by elevations of plasma fibrinogen and serum IL-6 levels. Thromb Haemost 2000; 84: 210-215.

52. Vgontzas AN, Papanicolaou DA, Bixler EO, et al. Sleep apnoea and daytime sleepiness and fatigue: relation to visceral obesity, insulin resistance, and hypercytokinemia. $J$ Clin Endocrinol Metab 2000; 85: 1151-1158.

53. Roytblat L, Rachinsky M, Fisher A, et al. Raised interleukin-6 levels in obese patients. Obes Res 2000; 8: 673-675.

54. Yokoe T, Minoguchi K, Matsuo H, et al. Elevated levels of C-reactive protein and interleukin-6 in patients with obstructive sleep apnoea syndrome are decreased by nasal continuous positive airway pressure. Circulation 2003; 107: $1129-1134$.

55. Alberti A, Sarchielli P, Gallinella E, et al. Plasma cytokine levels in patients with obstructive sleep apnoea syndrome: a preliminary study. J Sleep Res 2003; 12: 305-311.

56. Klausen T, Olsen NV, Poulsen TD, Richalet JP, Pedersen BK. Hypoxemia increases serum interleukin-6 in humans. Eur J Appl Physiol Occup Physiol 1997; 76: 480-482.

57. Entzian P, Linnemann K, Schlaak M, Zabel P. Obstructive sleep apnoea syndrome and circadian rhythms of hormones and cytokines. Am J Respir Crit Care Med 1996; 153: 10801086.

58. Drenth JP, Van Uum SH, Van Deuren M, Pesman GJ, Van der Ven-Jongekrijg J, van der Meer JW. Endurance run increases circulating IL-6 and IL-1ra but downregulates ex vivo TNF-alpha and IL-1 beta production. J Appl Physiol 1995; 79: 1497-1503.

59. Steensberg A, Febbraio MA, Osada T, et al. Interleukin-6 production in contracting human skeletal muscle is influenced by pre-exercise muscle glycogen content. J Physiol 2001; 537: 633-639.

60. van Hall G, Steensberg A, Sacchetti M, et al. Interleukin-6 stimulates lipolysis and fat oxidation in humans. J Clin Endocrinol Metab 2003; 88: 3005-3010.

61. Faldt J, Wernstedt I, Fitzgerald SM, Wallenius K, Bergstrom G, Jansson JO. Reduced exercise endurance in interleukin-6 deficient mice. Endocrinology 2004; 145: 2680-2686.

62. Starkie R, Ostrowski SR, Jauffred S, Febbraio M, Pedersen BK. Exercise and IL-6 infusion inhibit endotoxin-induced TNF-alpha production in humans. FASEB J 2003; 17: 884 886.

63. Reid MB, Li YP. Tumour necrosis factor-alpha and muscle wasting: a cellular perspective. Respir Res 2001; 2: 269-272. 
64. Debigare $\mathrm{R}$, Cote $\mathrm{CH}$, Maltais F. Peripheral muscle wasting in chronic obstructive pulmonary disease. Clinical relevance and mechanisms. Am J Respir Crit Care Med 2001; 164: $1712-1717$.

65. Wouters EF, Creutzberg EC, Schols AM. Systemic effects in COPD. Chest 2002; 121: 127S-130S.

66. Krueger JM, Obal FJ, Fang J, Kubota T, Taishi P. The role of cytokines in physiological sleep regulation. Ann N Y Acad Sci 2001; 933: 211-221.

67. Chrousos GP. The hypothalamic-pituitary-adrenal axis and immune-mediated inflammation. N Engl J Med 1995; 332: 1351-1362.

68. Watanabe $\mathrm{T}$, Morimoto A, Tan N, et al. ACTH response induced in capsaicin-desensitized rats by intravenous injection of interleukin-1 or prostaglandin E. J Physiol 1994; 475: 139-145.

69. Mastorakos G, Chrousos GP, Weber JS. Recombinant interleukin-6 activates the hypothalamic-pituitary-adrenal axis in humans. J Clin Endocrinol Metab 1993; 77: 16901694.

70. Turnbull AV, Rivier CL. Regulation of the hypothalamicpituitary-adrenal axis by cytokines: actions and mechanisms of action. Physiol Rev 1999; 79: 1-71.

71. Perlstein RS, Whitnall MH, Abrams JS, Mougey EH, Neta R. Synergistic roles of interleukin-6, interleukin-1, and tumour necrosis factor in the adrenocorticotropin response to bacterial lipopolysaccharide in vivo. Endocrinology 1993; 132: $946-952$.

72. Hussain SN, Magder S, Chatillon A, Roussos C. Chemical activation of thin-fiber phrenic afferents: respiratory responses. J Appl Physiol 1990; 69: 1002-1011.

73. Graff GR, Gozal D. Cardiorespiratory responses to interleukin-1beta in adult rats: role of nitric oxide, eicosanoids and glucocorticoids. Arch Physiol Biochem 1999; 107: 97112.

74. Preas HL, Jubran A, Vandivier RW, et al. Effect of endotoxin on ventilation and breath variability: role of cyclooxygenase pathway. Am J Respir Crit Care Med 2001; 164: 620-626.

75. Gosselin LE, Barkley JE, Spencer MJ, McCormick KM, Farkas GA. Ventilatory dysfunction in mdx mice: impact of tumour necrosis factor-alpha deletion. Muscle Nerve 2003; 28: $336-343$

76. Scardella AT, Edelman NH. Central fatigue in respiratory control. In: Charis Roussos, ed. The thorax. New York, Marcel Dekker Inc., 1995; pp. 1007-1025.

77. Petrozzino JJ, Scardella AT, Santiago TV, Edelman NH. Dichloroacetate blocks endogenous opioid effects during inspiratory flow-resistive loading. J Appl Physiol 1992; 72: 590-596.

78. Petrozzino JJ, Scardella AT, Edelman NH, Santiago TV. Respiratory muscle acidosis stimulates endogenous opioids during inspiratory loading. Am Rev Respir Dis 1993; 147: 607-615.

79. Scardella AT, Santiago TV, Edelman NH. Naloxone alters the early response to an inspiratory flow-resistive load. $J$ Appl Physiol 1989; 67: 1747-1753.

80. Scardella AT, Parisi RA, Phair DK, Santiago TV, Edelman NH. The role of endogenous opioids in the ventilatory response to acute flow-resistive loads. Am Rev Respir Dis 1986; 133: 26-31.

81. Wanke T, Lahrmann H, Auinger M, et al. Endogenous opioid system during inspiratory loading in patients with type I diabetes. Am Rev Respir Dis 1993; 148: 1335-1340.

82. Santiago TV, Remolina C, Scoles V III, Edelman NH. Endorphins and the control of breathing. Ability of naloxone to restore flow-resistive load compensation in chronic obstructive pulmonary disease. N Engl J Med 1981; 304: $1190-1195$.

83. Bellofiore S, Di Maria GU, Privitera S, Sapienza S, MilicEmili J, Mistretta A. Endogenous opioids modulate the increase in ventilatory output and dyspnoea during severe acute bronchoconstriction. Am Rev Respir Dis 1990; 142: 812-816. 